\title{
Interpretasi Bawah Permukaan Berdasarkan Distribusi Nilai Tahanan Jenis di Daerah Puspiptek, Serpong
}

\author{
Sub Surface Interpretation Based On \\ Resistivity Values Distribution in Puspitek Area, Serpong
}

\author{
Adhika Junara Karunianto*, Dwi Haryanto, Heri Syaeful, Dhatu Kamajati \\ Pusat Teknologi Bahan Galian Nuklir-BATAN, \\ Jl. Lebak Bulus Raya 09 Pasar Jumat, Jakarta, Indonesia, 12440 \\ *E-mail: adhika@batan.go.id
}

Naskah diterima: 14 November 2018, direvisi: 25 November 2018, disetujui: 30 November 2018

DOI: $10.17146 /$ eksplorium.2018.39.2.4968

\begin{abstract}
ABSTRAK
Kawasan Pusat Penelitian Ilmu Pengetahuan dan Teknologi (PUSPIPTEK) Serpong memiliki luas 460 hektar. Sebagian besar kawasan ini merupakan ruang terbuka hijau. Seiring dengan pertumbuhan kegiatan penelitian, kebutuhan sarana infrastruktur dan bangunan juga akan semakin meningkat. Sebagai sarana strategis nasional, diperlukan desin bangunan yang kokoh untuk dan sesuai dengan kondisi bawah permukaan. Survey geolistrik dapat digunakan untuk mengetahui kondisi/informasi di bawah permukaan tanah. Tujuan penelitian ini adalah memperoleh gambaran di bawah permukaan berdasarkan distribusi nilai geolistrik tahanan jenis di area rencana pembangunan Reaktor Daya Eksperimen (RDE). Pengambilan data tahanan jenis menggunakan alat ukur resistivitymeter multichannel tipe MAE X612EM+ secara 2-D menggunakan 48 channel konfigurasi WennerSchlumberger. Jumlah elektroda yang digunakan adalah 48 buah dengan interval jarak antar elektroda $5 \mathrm{~m}$. Berdasarkan pemodelan inversi 2-D telah dihasilkan empat model penampang lintasan yaitu line-1, line 2, line-3, dan line-4. Kesalahan data di tiap lintasan relatif kecil, kurang dari $12 \%$. Interpretasi geologi dilakukan pada pada penampang line-2 dan line-3 menggambarkan keberadaan lapisan A, B, dan C. Lapisan A diduga berupa batuan dengan ukuran butir lempung-lanau yang mengandung material organik dengan rentang nilai tahanan jenis $2-20 \Omega \mathrm{m}$ dan variasi ketebalan sekitar 1-7 m. Lapisan B diduga berupa batupasir yang memiliki rentang nilai tahanan jenis 10-90 $\Omega$ m dengan variasi ketebalan 5-20 m. Lapisan C diduga merupakan batulempung yang memiliki rentang nilai tahanan jenis 2-5000 $\Omega \mathrm{m}$ dengan variasi kedalaman 10-20 $\mathrm{m}$.
\end{abstract}

Kata kunci: geolistrik, tahanan jenis, multichannel, pemodelan, Wenner-Schlumberger

\section{ABSTRACT}

The area of Center for Research in Science and Technology (PUSPIPTEK) Serpong is 460 hectares wide. Most of the area is a Green Open Spaces (RTH). In the line with the growth of research activities, the need for infrastructure and building facilities also increases. As a national strategic facility, it is necessary to design buildings that are sturdy for and suitable with subsurface conditions. Geolectrical survey can be used to determine of subsurface condition/information. The purpose of this study is to obtain the ilustration of subsurface, based on the distribution of geoelectric resistivity values in the site of Experimental Power Reactor (RDE) construction. The resistivity data acquisition is using a multichannel resistivitymeter MAE X612EM+ type in 2-D by 48 channel of Wenner-Schlumberger configuration. The numbers of elctrodes used are 48 with an electrode interval of $5 \mathrm{~m}$. Based on 2-D inversion model, there are four section models obtained, namely line-1, line 2, line-3, and line-4. The data error for each section is relatively small, less than 12\%. Geological interpretation carried out in the section line-2 and line-3 illustrates the existence of layers $A, B$, and $C$. Layer A is interpreted as rock with silt to clay grain size containing organic material with resistivity values range 2-20 $\Omega \mathrm{m}$ and thickness varries in 1-7 $\mathrm{m}$. Layer $B$ is interpreted as sandstone which has a range of resistivity values from 10-90 $\Omega \mathrm{m}$ with thickness variations 5-20 m. Layer $C$ is interpreted as claystone which has a range of resistivity values from 2-5000 $\Omega m$ with depth variation in $10-20 \mathrm{~m}$.

Keywords: geoelectric, resistivity, multichannel, modeling, Wenner-Schlumberger 


\section{PENDAHULUAN}

Pusat Penelitian Ilmu Pengetahuan dan Teknologi (PUSPIPTEK) merupakan unit kerja di bawah Kementerian Riset, Teknologi, dan Pendidikan Tinggi didirikan berdasarkan Keputusan Presiden nomor 43/1976 tanggal 1 Oktober $1976 \quad$ [1]. Terdapat 50 Pusat/Balai/Balai Besar dalam Kawasan PUSPIPTEK yang terdiri atas 3 LPNK (BATAN, BPPT, dan LIPI) dan 2 Kementerian (Kementerian Riset, Teknologi, dan Pendidikan Tinggi; dan Kementerian Lingkungan Hidup dan Kehutanan). Kawasan ini berdiri di atas lahan seluas 460 hektar. Sebagian besar kawasan merupakan ruang terbuka hijau (RTH). Sejalan dengan pertumbuhan dan perkembangan dalam bidang penelitian, kebutuhan akan sarana dan prasarana juga akan mengalami peningkatan. Salah satu sarana yang diperlukan berupa bangunan/ gedung baru.

Sebagai pusat penelitian yang merupakan sarana strategis, bangunan dan infrastruktur didalamnya harus kuat, tahan lama, dan tepat guna. Suatu bangunan yang berdiri di atas tanah akan menimbulkan beban terhadap tanah hingga bawah permukaan. Tanah akan mengalami tegangan tergantung dari kelas tanah, beban dan luas pondasi yang digunakan [2]. Akibatnya terjadi tegangan bawah permukaan, sehingga timbul perubahan bentuk (deformasi) dan penurunan (settlement) terhadap bangunan yang bersangkutan [3]. Oleh karena itu perlu adanya perencanaan yang baik untuk mencegah timbulnya perubahan bentuk dan penurunan pada bangunan [4]. Kondisi bawah permukaan dan tata lingkungan perlu diperhatikan untuk mengurangi resiko perubahan bentuk dan penurunan [5].
Salah satu metode geofisika yang dapat digunakan untuk mengetahui kondisi bawah permukaan adalah geolistrik. Survei geolistrik sudah banyak diaplikasikan di beberapa bidang penelitian seperti hidrogeologi, lingkungan, teknik sipil serta prospeksi mineral karena kemampuannya yang cukup efektif memetakan distribusi tahanan jenis bawah permukaan [6]. Khususnya dalam bidang teknik sipil, sekarang ini kebutuhan data geolistrik sebagai data dukung sudah semakin penting.

Gambaran daerah penelitian berdasarkan peta geologi yang dipublikasikan oleh Pusat Penelitian dan Pengembangan Geologi, Bandung (Gambar 1) menunjukkan bahwa Kawasan PUSPIPTEK Serpong termasuk dalam wilayah peta geologi lembar Jakarta yang tersusun atas: sebaran Alluvial (Qa), Tufa pasiran Endapan Gunungapi Muda (Qv), Formasi Serpong (Tpss), Formasi Genteng (Tpg), dan Formasi Bonjongmanik (Tmb) dengan perubahan variasi litologi baik secara vertikal maupun lateral. Daerah penelitian berada pada Formasi Serpong dengan litologi batuannya adalah perselingan konglomerat, batupasir, batulanau, dan batulempung dengan sisa tanaman, konglomerat batuapung serta tuf batuapung [7]. Hasil identifikasi struktur geologi permukaan menunjukkan tidak adanya patahan kapabel dekat permukaan pada sekitar radius $5 \mathrm{~km}$ dari rencana lokasi tapak Reaktor Daya Eksperimen (RDE) yang berada di dalam kawasan PUSPIPTEK Serpong [8, 9]. Area pengambilan data geolistrik ini berada di dalam Kawasan PUSPIPTEK Serpong, Kota Tangerang Selatan, Provinsi Banten. 


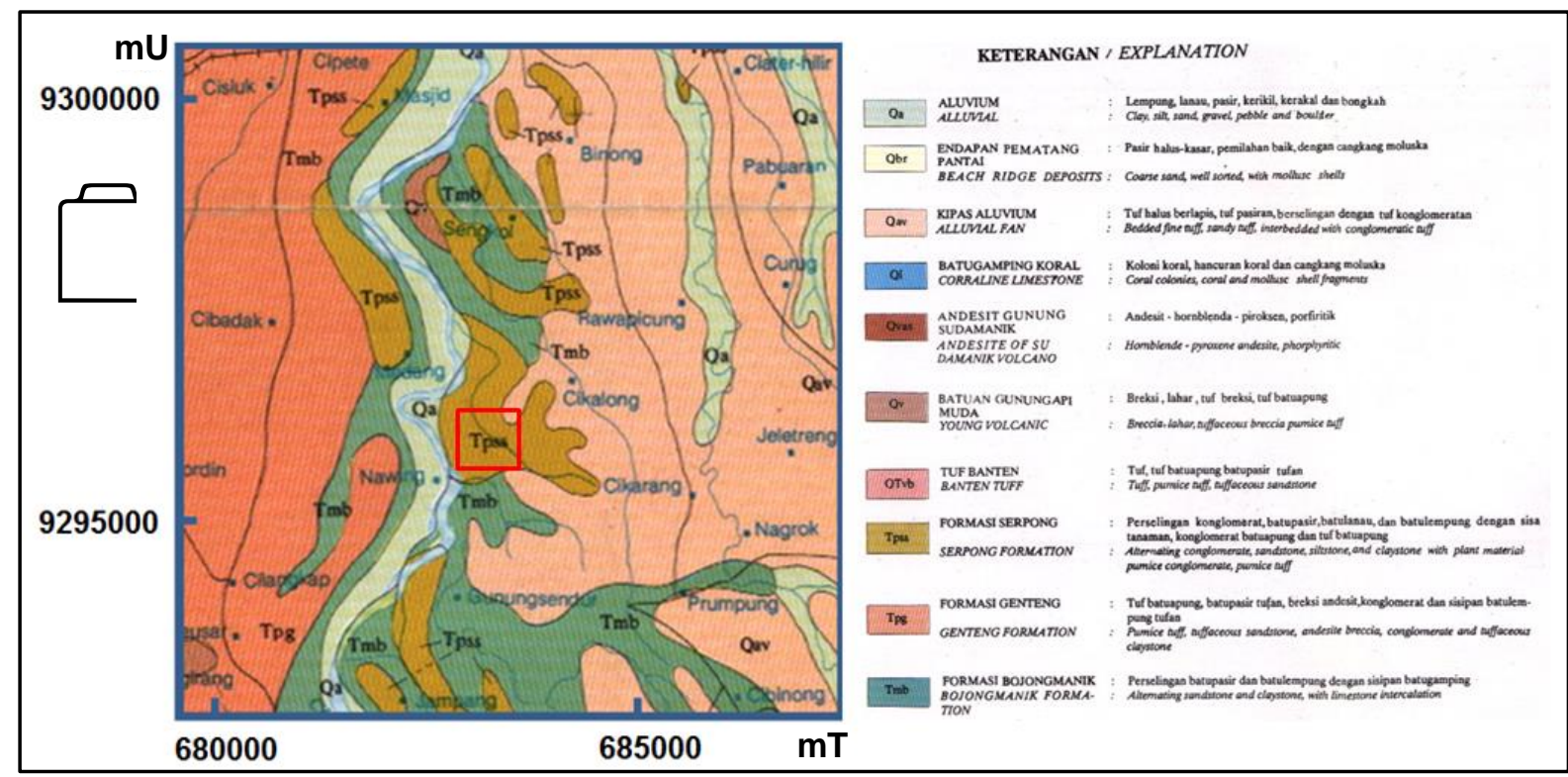

Gambar 1. Peta geologi regional dan daerah penelitian dengan simbol kotak merah (tanpa skala) [7].

Tujuan penelitian ini adalah memperoleh gambaran bawah permukaan berdasarkan distribusi nilai geolistrik tahanan jenis di area rencana pembangunan RDE. Pengukuran data tahanan jenis ini dilakukan secara lintasan/2-D dengan menggunakan konfigurasi WennerSchlumberger, kemudian selanjutnya dilakukan pemodelan secara 2-D untuk menghasilkan penampang distribusi tahanan jenis sebenarnya. Harapannya hasil penelitian ini dapat dijadikan sebagai referensi/acuan dalam perencanaan geoteknik dalam pembuatan bangunan-bangunan penting di dalam Kawasan PUSPIPTEK Serpong.

\section{TEORI}

Metode geolistrik tahanan jenis merupakan salah satu teknik geofisika yang digunakan untuk menyelidiki kondisi bawah permukaan tanah dengan memanfaatkan sifat fisis dari kelistrikan batuan. Besaran fisika yang diukur pada metode ini adalah perbedaan potensial listrik dengan cara melakukan injeksi arus listrik dengan ukuran tertentu sesuai ukuran kedalaman sehingga nantinya harga tahanan jenisnya dapat dihitung $[10,11]$.
Hukum Ohm menyatakan bahwa beda potensial $(\Delta \mathrm{V})$ pada medium dengan beban berupa tahanan listrik (R) akan berbanding lurus dengan perkalian arus listrik (I) dan $R$ yang ditunjukkan oleh persamaan berikut ini:

$$
\Delta V=I R
$$

Konsep dasar pengukuran tahanan jenis batuan diadopsi dari pengukuran tahanan jenis terhadap suatu sampel material di laboratorium yang skemanya diberikan pada Gambar 2. Nilai tahanan jenis suatu material tertentu didefinisikan seperti pada persamaan berikut ini:

$$
\rho=R \frac{A}{L}
$$

$$
\rho
$$

Nilai $\rho$ adalah tahanan jenis material, $R$ adalah tahanan yang diukur dengan satuan $\mathrm{Ohm}(\Omega)$, $L$ adalah panjang penampang dengan satuan meter dan $A$ adalah luas penampang dengan satuan $\mathrm{m}^{2}$. Jika persamaan (1) disubstitusikan ke dalam persamaan (2) maka akan diperoleh persamaan seperti berikut ini: 


$$
\rho=\frac{\Delta V}{I} \cdot \frac{A}{L}
$$

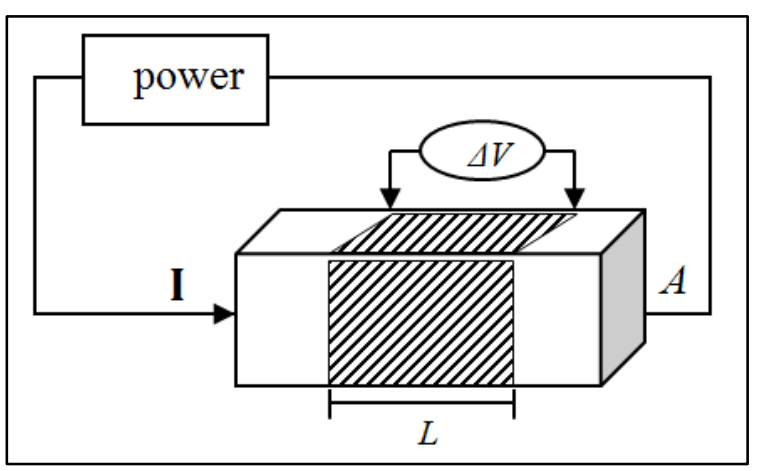

Gambar 2. Gambaran Hukum Ohm di dalam medium yang dialiri arus listrik [10].

Metode polarisasi terinduksi mengukur adanya polarisasi di dalam medium karena pengaruh arus listrik yang melewatinya. Polarisasi banyak terjadi pada medium yang mengandung mineral logam (misalnya senyawa sulfida logam) sehingga metode ini lebih banyak dipakai untuk eksplorasi mineral logam.

Bentuk energi yang tersimpan pada medium dapat berupa energi mekanik dan energi kimia. Penyimpanan energi kimia ini dapat disebabkan oleh variasi mobilitas ion dalam fluida yang terkandung dalam medium (efek pertama) dan variasi antara konduktivitas elektrolit dan elektron dalam medium yang mengandung mineral logam (efek kedua). Akibat efek pertama menghasilkan polarisasi membran atau polarisasi elektrolit dan merupakan efek dasar atau disebut juga efek normal dari polarisasi terinduksi. Kondisi ini terjadi pada batuan yang tidak mengandung mineral-mineral logam. Akibat efek kedua dikenal dengan polarisasi elektroda atau overvoltage. Efek polarisasi elektroda biasanya lebih besar dari efek polarisasi membran. Besar efek polarisasi elektroda tergantung pada kandungan mineral logam yang ada dalam batuan [12].

\section{METODOLOGI}

Secara umum tahapan metodologi penelitian terdiri atas tiga yaitu pengambilan data/akusisi lapangan, pengolahan data, dan analisa/interpretasi. Tahapan pengambilan data tahanan jenis dilakukan dengan menggunakan alat ukur resistivitymeter multichannel MAE X612EM+ (Gambar 3). Sistem pengukurannnya per lintasan secara 2D menggunakan 48 channel. Jumlah elektroda yang digunakan adalah 48 buah, dengan interval jarak pemasangan antar elektroda $5 \mathrm{~m}$. Konfigurasi pengukuran yang digunakan adalah Wenner-Schlumberger. Jumlah lintasan pengukuran adalah 4 lintasan yang terbagi menjadi 3 lintasan arah utara-selatan dan 1 lintasan arah barat-timur (Gambar 4). Panjang masing-masing lintasan adalah $235 \mathrm{~m}$ dengan jarak antar lintasan $30 \mathrm{~m}$. Lama pengukuran sekitar 6 jam yang terbagi 2 untuk persiapan bentang kabel dan koneksi, sedangkan 3-4 jam pengukuran harga tahanan jenis semu.

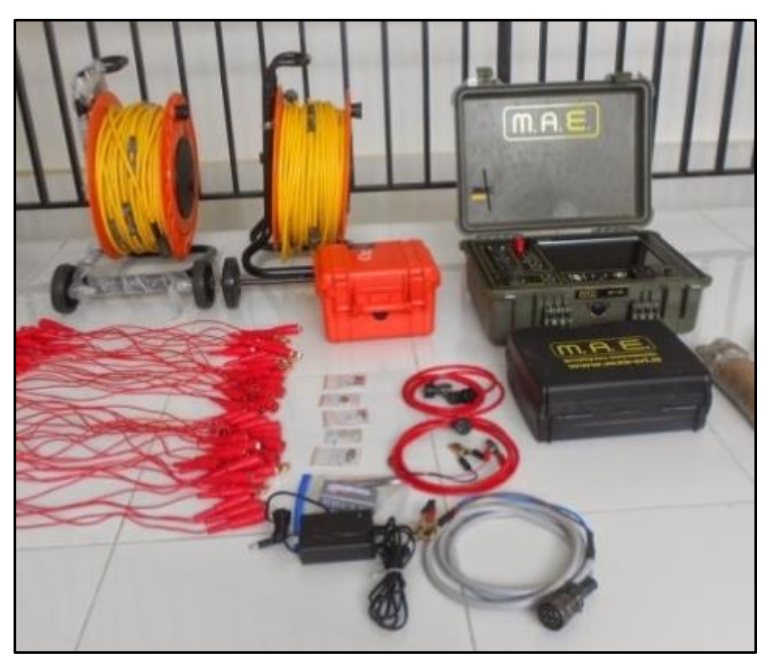

Gambar 3. Alat ukur resistivitymeter multichannel MAE X612EM+. 


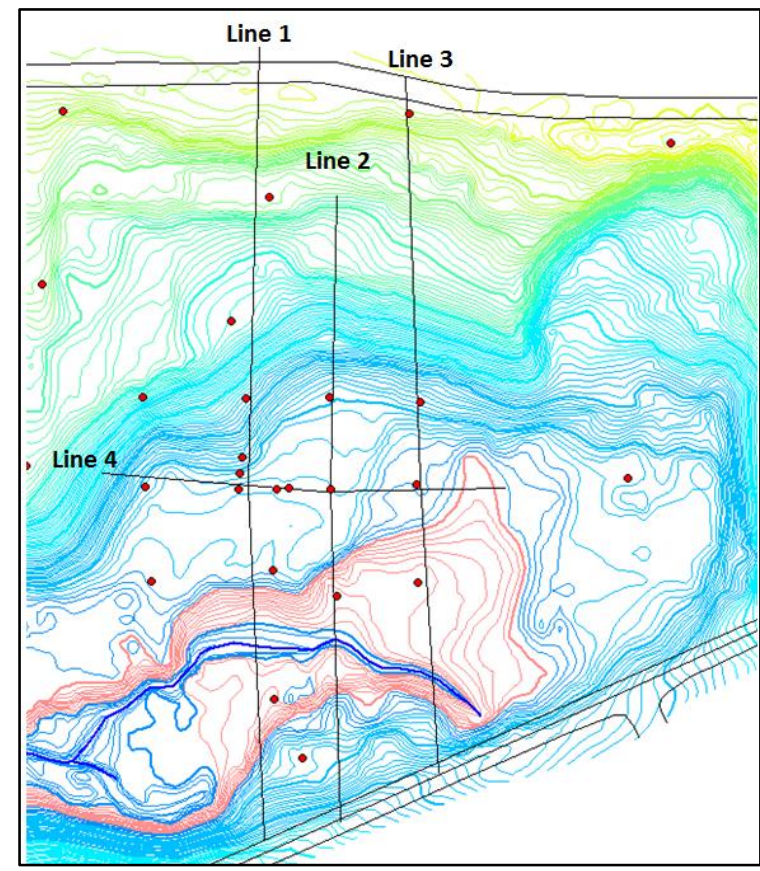

Gambar 4. Lokasi lintasan pengukuran geolistrik: line 1, 2, 3 arah U-S, sedangkan line 4 berarah B-T.

Pengolahan data tahanan jenis hasil pengukuran di lapangan yang masih merupakan data tahanan jenis semu (apparent resistivity) menggunakan teknik pemodelan inversi 2-D. Perangkat lunak aplikasi untuk pengolahan data yang digunakan adalah Res2Dinv versi 3.56. Perangkat lunak tersebut sudah sangat terkenal di kalangan para ahli geofisika. Hasil pemodelan berupa citra/image penampang vertikal 2-D dengan sumbu horisontal adalah jarak dan sumbu vertikal adalah kedalaman. Penampang ini memperlihatkan sebaran data bawah permukaan berupa tahanan jenis sebenarnya (true resistivity). Sebaran data tahanan jenis sebenarnya tersebut merupakan metoda pendekatan untuk melihat gambaran kondisi geologi di bawah permukaan [13].

Teknik pemodelan sama juga berlaku untuk data polarisasi terinduksi hasil pengukuran di lapangan yang menghasilkan penampang 2-D berupa sebaran data chargeability di bawah permukaan. Pemodelan inversi data polarisasi terinduksi ini umumnya dilakukan bersamaan dengan data tahanan jenis, sehingga akan menghasilkan penampang vertikal yang saling melengkapi yang bermanfaat untuk pekerjaan tahap analisis/interpretasi [13].

\section{HASIL DAN PEMBAHASAN}

Hasil pemodelan secara 2-D telah menghasilkan penampang distribusi tahanan jenis dan polarisasi terinduksi bawah permukaan. Penampang yang dihasilkan sesuai dengan jumlah lintasan pengukuran yang terdiri 3 lintasan arah utara-selatan dan 1 lintasan arah barat-timur, sehingga total terdapat 4 lintasan pengukuran (Gambar 4).

Penampang Line-1 pada Gambar 5(a) adalah lintasan pengukuran dari arah selatan ke utara. Secara umum terlihat 3 lapisan, yaitu lapisan nilai tahanan jenis rendah/low resistivity $(0,1-10 \Omega \mathrm{m})$, menengah/medium resistivity (20-1000 $\Omega \mathrm{m})$ dan tinggi/high resistivity $(>5000 \Omega \mathrm{m})$. Lapisan tahanan jenis tinggi terdistribusi dari posisi koordinat $\mathrm{x}=50$ m sampai $100 \mathrm{~m}$, dengan kedalaman sekitar 5$20 \mathrm{~m}$.

Line-2 pada Gambar 5(b) adalah lintasan pengukuran dari arah selatan ke utara. Penampang ini terdiri dari 3 lapisan yaitu tahanan jenis rendah $(0,1-10 \Omega \mathrm{m})$, menengah $(20-1000 \Omega m)$ dan tinggi (>5000 $\Omega \mathrm{m})$. Lapisan tahanan jenis tinggi terdistribusi dari posisi koordinat $\mathrm{x}=55 \mathrm{~m}$ sampai $140 \mathrm{~m}$, dengan kedalaman sekitar 5-25 m.

Line-3 pada Gambar 5(c) adalah lintasan pengukuran dari arah selatan ke utara. Secara umum terlihat terdiri dari 3 lapisan yaitu tahanan jenis rendah (0,1-10 $\Omega \mathrm{m})$, menengah (20-1000 $\Omega \mathrm{m})$ dan tinggi (>5000 $\Omega \mathrm{m})$. Lapisan tahanan jenis tinggi terdistribusi dari posisi koordinat $\mathrm{x}=60 \mathrm{~m}$ sampai $150 \mathrm{~m}$, dengan kedalaman sekitar 5-25 m. 
Gambar 5(d) adalah Line-4 yang merupakan lintasan pengukuran dari arah barat ke timur. Lintasan ini berpotongan dengan Line-1 pada posisi jarak antara 90-95 m ditandai dengan garis panah warna merah (Gambar 5(a) dan 5(d)). Perpotongan dengan Line-2 pada posisi jarak horizontal antara 110$115 \mathrm{~m}$ ditandai dengan garis panah warna biru muda (lihat Gambar 5(b) dan 5(d)). Perpotongan dengan Line-3 pada posisi jarak datar antara 110-115m ditandai dengan garis panah warna hijau muda (Gambar 5(c) dan 5(d)). Secara umum Line-4 terdiri dari 3 lapisan yaitu tahanan jenis rendah (0,1-10 $\Omega \mathrm{m})$, menengah (20-1000 $\Omega \mathrm{m}$ ) dan tinggi $(>5000 \Omega \mathrm{m})$. Lapisan tahanan jenis tinggi terdistribusi dari posisi koordinat $\mathrm{x}=50 \mathrm{~m}$ sampai $100 \mathrm{~m}$, dengan kedalaman sekitar 5-30 $\mathrm{m}$.

Selain dilakukan pengukuran tahanan jenis juga dilakukan pengukuran polarisasi terinduksi/chargebility (Gambar 6) yang berada pada lintasan yang sama dari Line-1 sampai dengan Line-4. Secara keseluruhan penampang terlihat ada dua lapisan yaitu chargeability rendah dan tinggi. Chargeability rendah memiliki kisaran nilai 0-10 mdet, sedangkan chargeability tinggi dengan kisaran $>100$ mdet. Sebaran lapisan chargeability tinggi hampir merata di semua penampang lintasan pengukuran.

Interpretasi geologi bawah permukaan penampang geolistrik dapat dilihat pada Gambar 7 dan 8. Penampang pada Gambar 7 merupakan gambaran distribusi tahanan jenis bawah permukaan pada Line-2 (Gambar 4). Penampang ini terbagi menjadi tiga (3) lapisan yaitu lapisan A, B dan C. Lapisan A merupakan lapisan batuan berukuran butir lempung-lanau yang mengandung material organik. Lapisan ini memiliki variasi nilai tahanan jenis antara 2-20 $\Omega \mathrm{m}$ dengan ketebalan sekitar 1-7 m dari permukaan tanah.
Lapisan B merupakan batuan berukuran butir pasir yang terdapat sisipan lempung dan lanau. Lapisan batuan ini memiliki variasi harga tahanan jenis antara 10-90 $\Omega \mathrm{m}$ dengan ketebalan sekitar 5-20 m. Dilihat dari arah penampang utara-selatan, lapisan ini memiliki ketebalan relatif besar dibanding di ujungujung penampang. Lapisan C merupakan batulempung yang terdapat sisipan pasir. Lapisan batuan ini memiliki variasi nilai tahanan jenis paling lebar dibanding lapisanlapisan di atasnya yaitu mulai dari $2 \Omega \mathrm{m}$ hingga lebih dari $5000 \Omega \mathrm{m}$ dengan kedalaman sekitar 10 sampai $20 \mathrm{~m}$. Dilihat dari arah penampang utara-selatan, lapisan ini memiliki ketebalan relatif besar di bagian tengah dibandingkan pada ujung-ujung penampang. Pada posisi jarak horizontal $80 \mathrm{~m}$ dari selatan dengan kedalaman kurang lebih sekitar $20 \mathrm{~m}$, terdapat suatu zona tahanan jenis relatif tinggi (high resistivity zone) dan harga chargeability juga tinggi antara 200-500 mdet. Zona ini kemungkinan merupakan batulempung pasiran yang lebih masif dan padat.

Penampang pada Gambar 8 merupakan gambaran distribusi tahanan jenis bawah permukaan pada Line-3 yang terletak di sebelah timur Line-2 (Gambar 4). Pola struktur geologi bawah permukaan penampang ini relatif sama pada Line-2 karena beda jaraknya relatif kecil sekitar $30 \mathrm{~m}$. Penampang ini terbagi menjadi 3 lapisan yaitu lapisan A, B, dan C. Lapisan A merupakan lapisan tanah berukuran butir lempung-lanau yang mengandung material organik. Lapisan ini memiliki variasi nilai tahanan jenis 2-20 $\Omega$ m dengan ketebalan sekitar 1-5 m dari permukaan tanah. Lapisan B merupakan batupasir yang terdapat sisipan lempung dan lanau. Lapisan batuan ini memiliki variasi harga tahanan jenis 10-90 $\Omega \mathrm{m}$ dengan ketebalan sekitar 5-20 m. Dilihat dari arah 
penampang utara-selatan lapisan ini memiliki ketebalan relatif besar dibanding di ujungujung penampang.

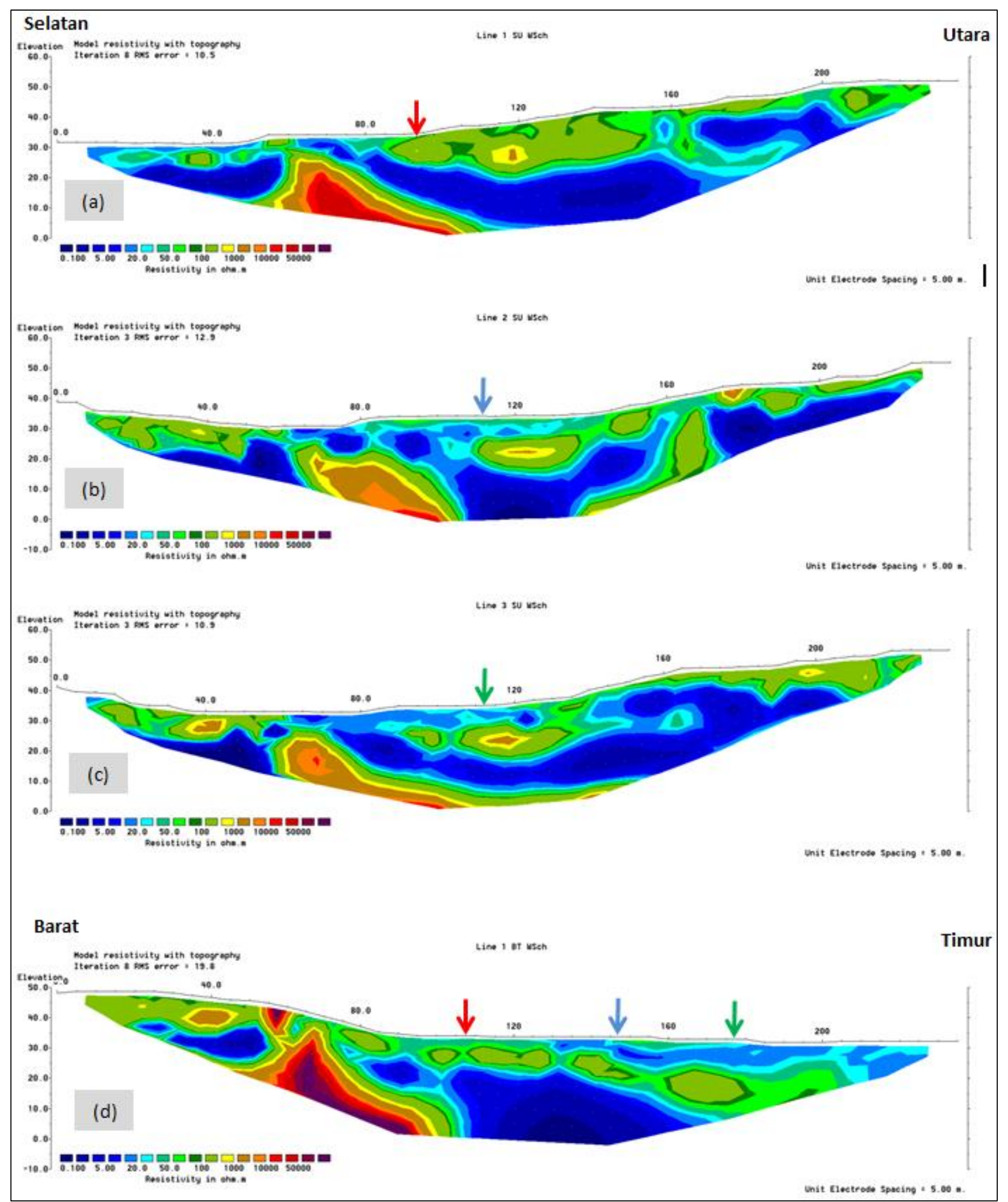

Gambar 5. Penampang sebaran tahanan jenis yang terdiri dari lintasan arah Utara-Selatan: (a) Line-1, (b) Line-2, (c) Line-3, dan lintasan arah Barat-Timur (d) Line-4 (perpotongan penampang ditandai garis panah merah, biru dan hijau). 


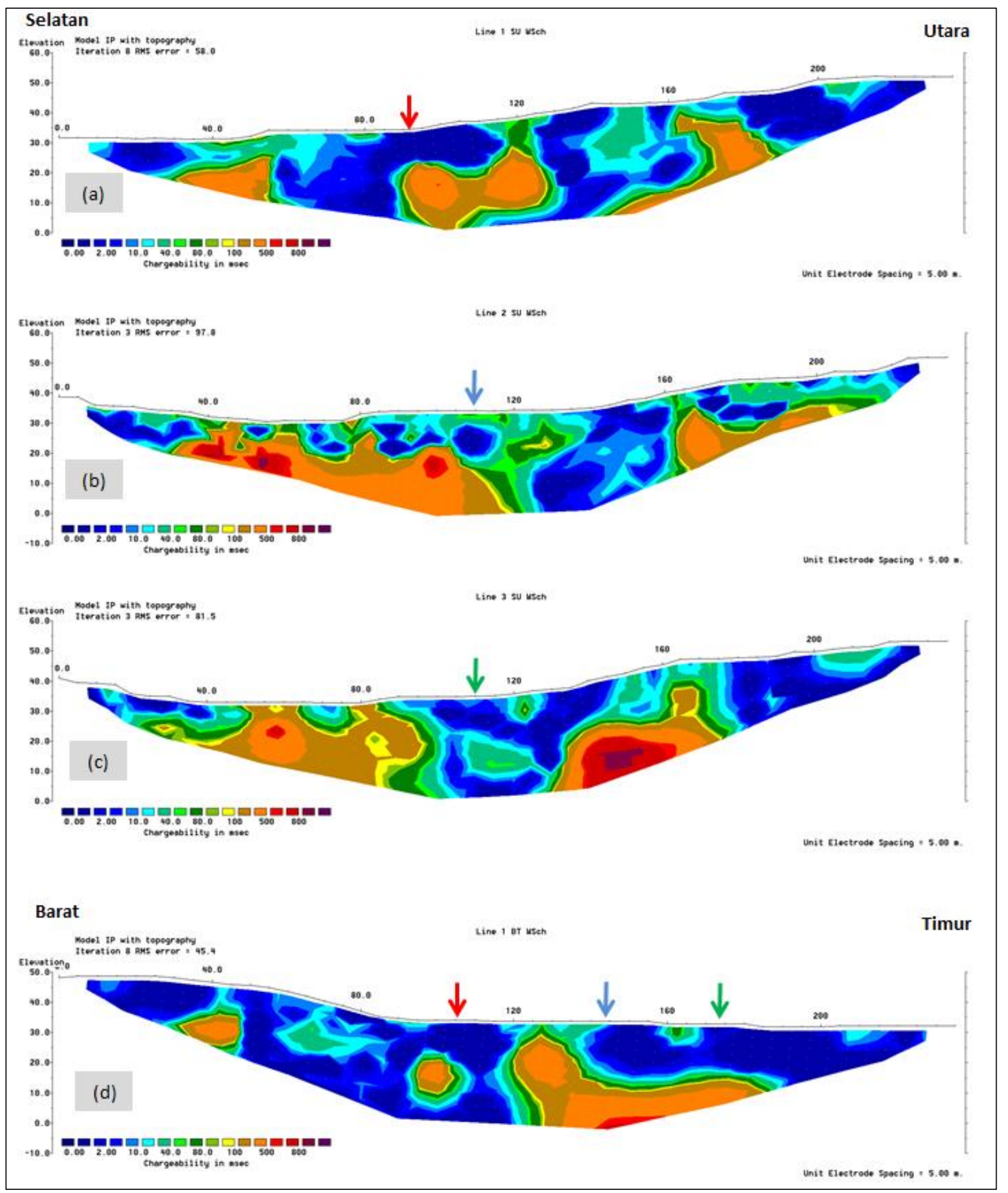

Gambar 6. Penampang sebaran chargeability yang terdiri dari lintasan arah Utara-Selatan: (a) Line-1, (b) Line-2, (c) Line-3, dan lintasan arah Barat-Timur (d) Line-4 (perpotongan penampang ditandai garis panah merah, biru, dan hijau). 


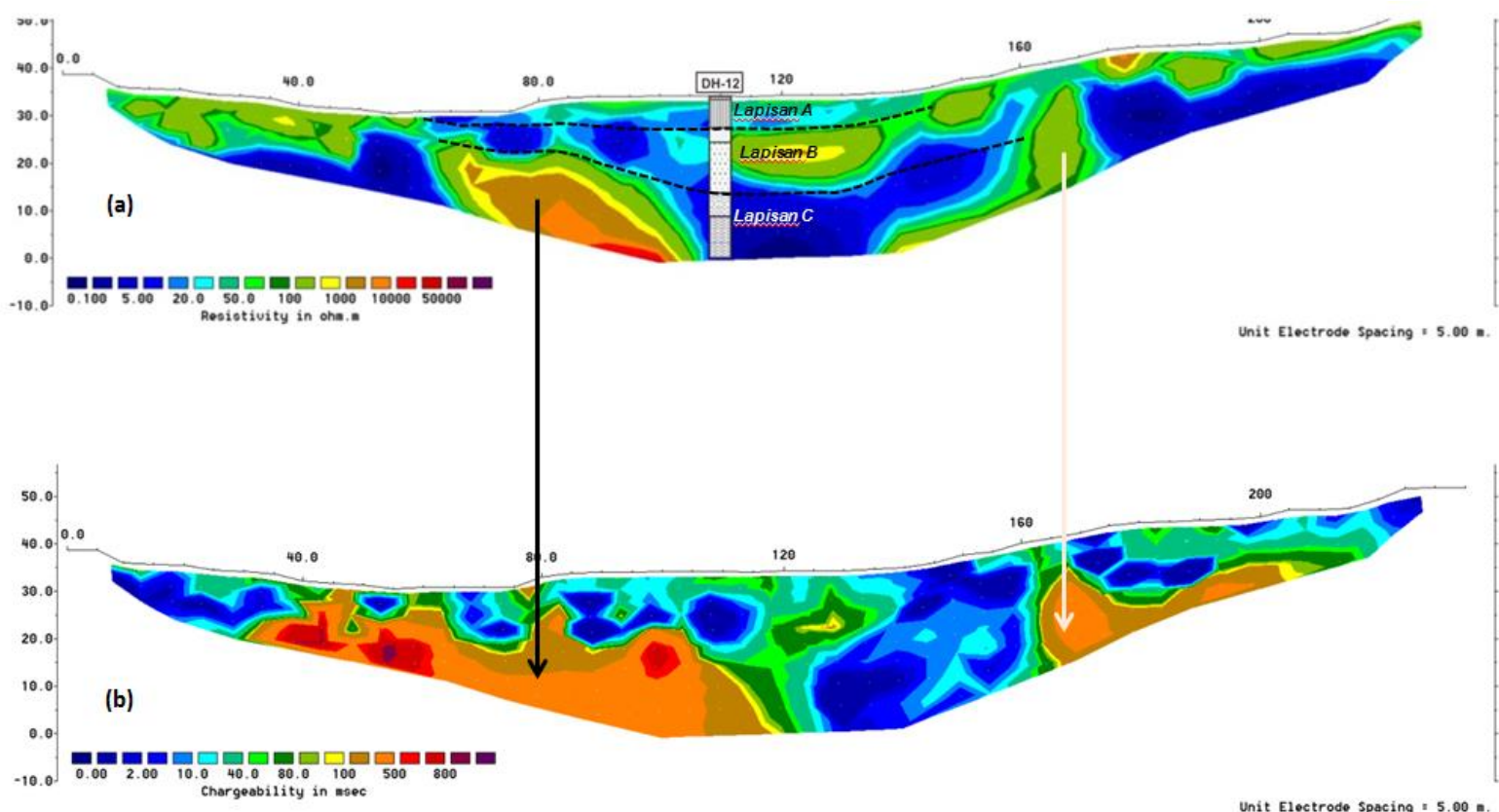

Gambar 7. Interpretasi penampang line-2; (a) tahanan jenis, (b) chargeability.

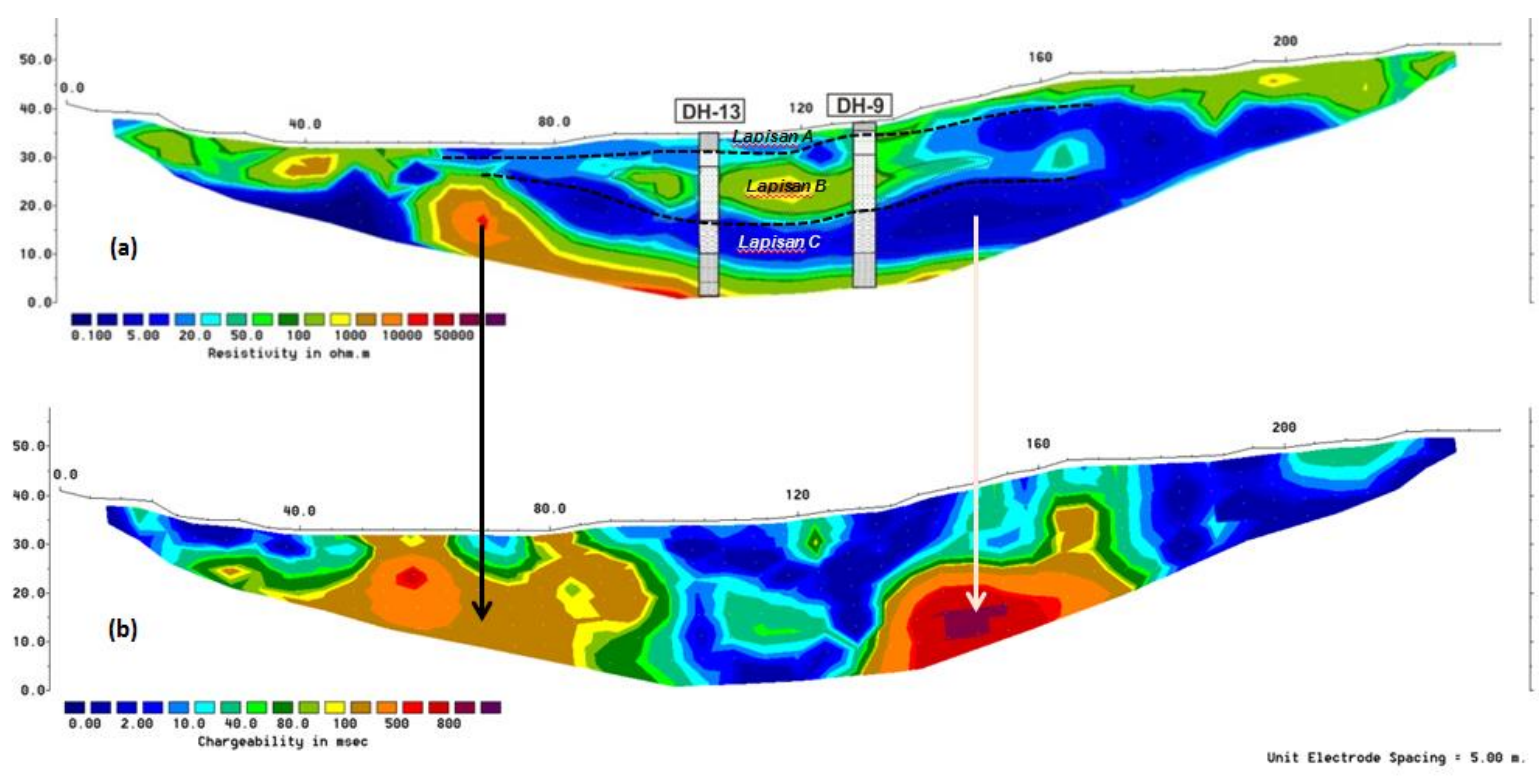

Gambar 8. Interpretasi penampang line-3; (a) tahanan jenis, (b) chargeability.

Lapisan C merupakan batulempung yang terdapat sisipan pasir. Lapisan batuan ini memiliki variasi nilai tahanan jenis paling lebar dibanding lapisan-lapisan di atasnya yaitu dari $2 \Omega \mathrm{m}$ sampai lebih dari $5000 \Omega \mathrm{m}$ dengan kedalaman sekitar 10-20 m. Terlihat dari sudut pandang arah penampang utaraselatan, lapisan ini memiliki ketebalan relatif besar di bagian tengah dibandingkan pada ujung-ujung penampang. Pada posisi jarak horizontal $80 \mathrm{~m}$ dari selatan dengan kedalaman kurang lebih sekitar 15-20 m terdapat suatu zona tahanan jenis relatif tinggi dan harga chargeability juga tinggi antara 200-500 mdet. Zona ini kemungkinan merupakan batulempung pasiran yang lebih masif dan padat. Sedangkan pada jarak horizontal sekitar 140-180 m terdapat zona degan harga tahanan 
jenis relatif rendah kurang dari $5 \Omega \mathrm{m}$, tetapi dengan nilai chargeability tinggi sekitar 400800 mdet. Kemungkinan pada zona ini lebih dominan mineral lempungnya.

\section{KESIMPULAN}

Pengukuran geolistrik tahanan jenis dengan konfigurasi Wenner-Schlumberger menghasilkan empat (4) penampang tahanan jenis dan chargeability yaitu Penampang Line1, Line-2, Line-3 dan Line-4. Hasil pemodelan data geolistrik menghasilkan kesalahan/error yang relatif kecil, yaitu kurang dari $12 \%$. Interpretasi geologi dilakukan pada pada penampang line-2 dan line-3 menggambarkan keberadaan lapisan A, B dan C. Lapisan A diduga berupa batuan dengan ukuran butir lempung-lanau mengandung material organik yang memiliki rentang nilai tahanan jenis 2-20 $\Omega \mathrm{m}$ dengan variasi ketebalan sekitar 1-7 m. Lapisan B diduga berupa batuan dengan ukuran butir pasir dengan sisipan lempung dan lanau yang memiliki rentang nilai tahanan jenis dari 10-90 $\Omega \mathrm{m}$ dengan variasi ketebalan 5-20 m. Lapisan C diduga berupa batulempung dengan sisipan pasir yang memiliki rentang nilai tahanan jenis dari 2-5000 $\Omega \mathrm{m}$ dengan variasi kedalaman 10-20 m.

\section{UCAPAN TERIMA KASIH}

Penulis mengucapkan terima kasih kepada Kepala PTBGN-BATAN atas dukungannya sehingga penelitian ini dapat diselesaikan. Ucapan terima kasih juga kami sampaikan kepada para Mentor/Trainer dari PT Andalan, Saudara Salmon (mahasiswa dari UNDIP Semarang), serta rekan kerja di PTBGNBATAN yang turut berperan aktif dalam kegiatan penelitian ini.

\section{REFERENSI}

[1] HUMAS PI Puspitek, "Profil Pusat Penelitian Ilmu Pengetahuan dan Teknologi (Puspiptek).” .

[2] Marjiyono, H. Suntoko, A. Soehaimi, Yuliastuti, and H. Syaeful, "Kelas Soil Daerah Sekitar Rencana Tapak Reaktor Daya Eksperimental (RDE) Serpong dari Data Mikrotremor," J. Pengemb. Energi Nukl., vol. 17, no. 1, pp. 57-66, 2015.

[3] Hurriyah and R. Jannah, "Analisis Struktur Lapisan Bawah Permukaan Menggunakan Metode Geolistrik (Studi Kasus pada Kampus III IAIN Imam Bonjol Padang di Sungai Bangek Kecamatan Koto Tangah)," J. Spasial, vol. 2, pp. 28-39, 2015.

[4] H. Syaeful, Sucipta, and I. A. Sadisun, "Studi Geologi Teknik Tapak Penyimpanan Akhir Limbah Radioaktif (LRA) Demo Plant Tipe NSD Kedalaman Menengah di Puspiptek, Serpong," Eksplorium, vol. 35, no. 1, pp. 13-28, 2014.

[5] Suntoko and Sriyana, "Penentuan Kedalaman Batuan Dasar Menggunakan Microtremor Array Di Tapak RDE Serpong," J. Pengemb. Energi Nukl., vol. 18, no. 2, pp. 87-92, 2016.

[6] A. P. Aizebeokhai and K. D. Oyeyemi, "The Use of The Multiple-Gradient Array for Geoelectrical Resistivity and Induced Polarization Imaging," J. Appl. Geophys., vol. 111, pp. 364-376, 2014.

[7] T. Turkandi, Sidarto, D. A. Agustianto, and M. M. P. Hadiwidjoyo, Peta Geologi Lembar Jakarta dan Kepulauan Seribu. Bandung: Puslitbang Geologi, 1992.

[8] H. Suntoko and A. B. Wicaksono, "Identifikasi Patahan pada Batuan Sedimen Menggunakan Metode Geolistrik Konfigurasi Dipole-Dipole di Tapak RDE Serpong, Banten," J. Pengemb. Energi Nukl., vol. 19, no. 2, pp. 81-88, 2017.

[9] Suntoko and Sriyana, "Identifikasi Patahan Menggunakan Analisis Data Deformasi Tanah di Tapak RDE Serpong Fault," J. Pengemb. Energi Nukl., vol. 38, no. 2, pp. 99-108, 2017.

[10] W. M. Telford, L. P. Geldart, and R. E. Sheriff, Applied geophysics, 2nd ed. New York: Cambridge University Press, 1990.

[11] P. Kearey, M. Brooks, and I. Hill, An Introduction to Geophysical Exploration, 3rd ed. Malden: Blackwell Science Ltd, 2002.

[12] H. Suntoko and A. B. Wicaksono, "Identifikasi Patahan pada Batuan Sedimen Menggunakan Metode Geolistrik Konfigurasi Dipole-Dipole di Tapak RDE Serpong, Banten," J. Pengemb. Energi Nukl., vol. 19, no. 2, pp. 81-88, 2017.

[13] M. H. Loke, Tutorial: 2-D and 3-D Electrical Imaging Surveys. Geotomo Software Inc., 2004. 